\title{
Current status of cerebral protection for aortic arch surgery
}

\author{
John S. Ikonomidis, MD, PhD
}

See related article on pages 2888-94.

The landmark article in 1975 by Griepp and colleagues ${ }^{1}$ describing 4 patients subjected to profound hypothermic circulatory arrest for aortic arch replacement represented a monumental advancement in our approach to surgery on the aortic arch. Since that time, innumerable reports have been published documenting different approaches to cerebral protection during aortic arch surgery. During this period, substantial focus was placed on the identification of safe temperatures for profound hypothermic circulatory arrest, followed by the introduction of adjunct perfusion strategies, either retrograde cerebral perfusion (RCP) or $\mathrm{ACP}$, intended to protect the brain further and prolong the safe period of profound hypothermic circulatory arrest. Evidence began to accumulate that the introduction of an adjunct perfusion strategy might offer advantages to deep hypothermic circulatory arrest alone, ${ }^{2,3}$ although some authors have reported outstanding success with straight deep hypothermic circulatory arrest. ${ }^{4}$ Interestingly, and perhaps not surprisingly, the use of these cerebral perfusion strategies has resulted in aortic surgeons' "pushing the envelope" to increase the minimum temperature for circulatory arrest by using a strategy of "mild to moderate hypothermia."

Two articles in the Journal of Thoracic and Cardiovascular Surgery address these issues. The first article, by Okita and colleagues, ${ }^{5}$ reports a study that examined a total of 16,280 patients listed in the Japan Adult Cardiovascular Surgery database who underwent total arch replacement between 2009 and 2012. In this series, 8169 patients were studied, 7038 of whom had hypothermic circulatory arrest with ACP and 1141 of whom had profound hypothermic circulatory arrest with or without RCP (HCA/RCP). From each of these groups, it was possible to draw for analysis 1141 patients for whom a nonmatched comparison was made and a propensity score analysis was performed. The matched paired analysis showed that the minimal rectal temperature was $3^{\circ} \mathrm{C}$

From the Division of Cardiothoracic Surgery, Medical University of South Carolina, Charleston, SC.

Disclosures: Author has nothing to disclose with regard to commercial support.

Received for publication Sept 24, 2014; accepted for publication Sept 24, 2014; available ahead of print Oct 18, 2014.

Address for reprints: John S. Ikonomidis, MD, PhD, Division of Cardiothoracic Surgery, Suite 7030, 25 Courtenay Dr, Charleston, SC 29425 (E-mail: ikonomij@musc.edu). J Thorac Cardiovasc Surg 2014;148:2466-7

$0022-5223 / \$ 36.00$

Copyright (C) 2014 by The American Association for Thoracic Surgery

http://dx.doi.org/10.1016/j.jtcvs.2014.09.085 higher at $24.2^{\circ} \mathrm{C}$ in the $\mathrm{ACP}$ group, with no significant differences between the groups with regard to 30-day mortality, stroke, or transient neurologic events. The HCA/RCP group, however, had significantly longer ventilation times and intensive care unit stays. The article has as limitations a lack of documentation of the total circulatory arrest times and cerebral perfusion rates, as well as wide variations in circulatory arrest temperatures in both groups. The HCA/RCP group is further heterogeneous in that not all patients had RCP for the entirety of the circulatory arrest period.

The second article, by Algarni and associates, ${ }^{6}$ reports a study that examined 128 patients with acute type A aortic dissections between 1990 and 2010 who underwent surgical repair in which either profound hypothermia (defined as circulatory arrest at a temperature $<20^{\circ} \mathrm{C}$, with a mean temperature in this series of $18^{\circ} \mathrm{C}$ ) or moderate hypothermia (defined as a temperature of $22^{\circ} \mathrm{C}-28^{\circ} \mathrm{C}$, with a mean of $24^{\circ} \mathrm{C}$ ) was used for interventions on the aortic arch. Formal arch replacement was performed in 7 of 75 patients in the moderate hypothermia group and 8 of 53 patients in the profound hypothermia group. The primary outcome was a composite outcome of major cardiac and cerebrovascular events defined as death, stroke, or low cardiac output syndrome during the index hospitalization. The results showed that the composite outcome was significantly worse in the profound hypothermia group. Cardiopulmonary bypass time and blood transfusions were significantly higher in the profound hypothermia group and use of profound hypothermia was an independent predictor of composite outcome according to multivariable analysis. This article has as limitations that this was an observational single-center study that used complex statistical analysis to control for confounders. Circulatory arrest times were relatively short $(25 \pm 13$ minutes for moderate hypothermia and $29 \pm 15$ minutes for profound hypothermia), reflective of primarily hemiarch replacements.

These 2 reports encapsulate some of the ongoing controversies and summarize current trends regarding cerebral protection strategies for aortic arch surgery. Retrograde cerebral perfusion was first introduced by Ueda and associates ${ }^{7}$ in 1990; they reported that safe circulatory arrest periods could be extended to as long as 80 minutes with this adjunct. Numerous authors have reported success with this strategy, but concerns have been raised regarding the adequacy of brain perfusion with this technique, ${ }^{8}$ as well as regarding increased incidence of transient neurologic dysfunction with longer circulatory arrest times. ${ }^{2}$ Antegrade cerebral perfusion, first described 
by Bachet and colleagues ${ }^{9}$ and Kazui and associates, ${ }^{10}$ maintains physiologic blood flow to the brain and can be delivered in a variety of ways. Analysis of the Japan Adult Cardiovascular Surgery database ${ }^{11}$ of procedures performed between 2005 and 2008 compared 2209 ACP cases with 583 RCP cases and showed no differences in 30-day mortality and stroke but a higher incidence of transient neurologic dysfunction in the RCP group. In contrast, a recent meta-analysis encompassing 15 studies and a total of 5060 patients showed no differences in 30-day mortality, permanent neurologic dysfunction, or transient neurologic dysfunction. ${ }^{12}$ The study by Okita and colleagues ${ }^{5}$ did not show differences in neurologic events, but it did document longer ventilation times and intensive care unit stay in the HCA/RCP group. The general consensus seems to be that the neuroprotective potential of RCP may be limited, and as result many centers have abandoned this technique in favor of ACP.

Trials from numerous centers from around the world have demonstrated the clinical efficacy of adult aortic arch repair with ACP and mild to moderate hypothermia in the range of $22^{\circ} \mathrm{C}$ to $30^{\circ} \mathrm{C}$. A contemporary review of questionnaires distributed at international conferences in Beijing and Milan in 2010 showed that the typical strategy for adult aortic arch repair was moderate hypothermia with bilateral ACP, with that strategy particularly prevalent in Europe. ${ }^{13}$ Tian and colleagues ${ }^{14}$ reported a meta-analysis of 9 studies and 1783 patients in which 813 patients received deep hypothermic circulatory arrest and 970 patients received moderate hypothermia and ACP. The results showed a significant reduction in stroke in the moderate hypothermia group, with comparable results observed for transient neurologic deficits, mortality, renal failure, and bleeding. The study by Algarni and associates ${ }^{6}$ identified the use of profound hypothermia as a predictor of adverse outcome. Further scrutiny of the study of Okita and colleagues ${ }^{5}$ reveals that only $36.7 \%$ of patients in the ACP group and $9.6 \%$ of patients in the HCA/RCP group had the lowest arrest temperatures below $20^{\circ} \mathrm{C}$, with $43.9 \%$ in the ACP and $18.1 \%$ in the $\mathrm{HCA} / \mathrm{RCP}$ having the lowest temperatures no lower than $25^{\circ} \mathrm{C}$. Both studies highlight the trend toward the use of mild to moderate hypothermia.

The potential benefits of limiting cooling are obvious, with shorter cardiopulmonary bypass and operative times and potentially decreased bleeding and accumulation of cardiac and systemic edema. These advantages, however, are offset by concerns regarding adequacy of spinal cord and end-organ protection, especially with longer arrest times. Although these latter issues remain incompletely addressed, the evidence base is clear that the use of moderate hypothermia with antegrade cerebral perfusion represents a paradigm shift, perhaps for the better, in the cerebral protection strategy for thoracic aortic surgeons around the world.

\section{References}

1. Griepp RB, Stinson EB, Hollingsworth JF, Beuhler D. Prosthetic replacement of the aortic arch. J Thorac Cardiovasc Surg. 1975;70:1051-63.

2. Hagl C, Ergin MA, Galla JD, Lansman SL, McCullough JN, Spielvogel D, et al. Neurologic outcome after ascending aorta-aortic arch operations: effect of brain protection technique in high-risk patients. J Thorac Cardiovasc Surg. 2001;121: 1107-21.

3. Misfeld M, Mohr FW, Etz CD. Best strategy for cerebral protection in arch surgery-antegrade selective cerebral perfusion and adequate hypothermia. Ann Cardiothorac Surg. 2013;2:331-8.

4. Ziganshin BA, Rajbanshi BG, Tranquilli M, Fang H, Rizzo JA, Elefteriades JA. Straight deep hypothermic circulatory arrest for cerebral protection during aortic arch surgery: safe and effective. J Thorac Cardiovasc Surg. 2014;148:888-98; discussion 898-900.

5. Okita Y, Miyata H, Motomura N, Takamoto S. A study of brain protection during total arch replacement comparing cerebral perfusion versus hypothermic circulatory arrest, with or without retrograde cerebral perfusion: analysis based on the Japan Adult Cardiovascular Surgery Database. J Thorac Cardiovasc Surg. October 22, 2014 [Epub ahead of print].

6. Algarni KD, Yanagawa B, Rao V, Yau TM. Profound hypothermia compared with moderate hypothermia in repair of acute type A aortic dissection. J Thorac Cardiovasc Surg. 2014;148:2888-94.

7. Ueda Y, Miki S, Kusuhara K, Okita Y, Tahata T, Yamanaka K. Surgical treatment of aneurysms or dissection involving the ascending aorta and aortic arch, utilizing circulatory arrest and retrograde cerebral perfusion. J Cardiovasc Surg (Torino). 1990;31:553-8.

8. Ehrlich MP, Hagl C, McCullough JN, Zhang N, Shiang H, Bodian C, et al. Retrograde cerebral perfusion provides negligible flow through brain capillaries in the pig. J Thorac Cardiovasc Surg. 2001;122:331-8.

9. Bachet J, Guilmet D, Goudot B, Dreyfus GD, Delentdecker P, Brodaty D, et al Antegrade cerebral perfusion with cold blood: a 13-year experience. Ann Thorac Surg. 1999;67:1874-8; discussion 1891-4.

10. Kazui T, Inoue N, Yamada O, Komatsu S. Selective cerebral perfusion during operation for aneurysms of the aortic arch: a reassessment. Ann Thorac Surg. 1992;53:109-14.

11. Usui A, Miyata H, Ueda Y, Motomura N, Takamoto S. Risk-adjusted and case-matched comparative study between antegrade and retrograde cerebral perfusion during aortic arch surgery: based on the Japan Adult Cardiovascular Surgery Database: the Japan Cardiovascular Surgery Database Organization. Gen Thorac Cardiovasc Surg. 2012;60:132-9.

12. Hu Z, Wang Z, Ren Z, Wu H, Zhang M, Zhang H, et al. Similar cerebral protective effectiveness of antegrade and retrograde cerebral perfusion combined with deep hypothermia circulatory arrest in aortic arch surgery: a meta-analysis and systematic review of 5060 patients. J Thorac Cardiovasc Surg. 2014;148:544-60.

13. Gutsche JT, Feinman J, Silvay G, Patel PP, Ghadimi K, Landoni G, et al. Practice variations in the conduct of hypothermic circulatory arrest for adult aortic arch repair: focus on an emerging European paradigm. Heart Lung Vessel. 2014;6:43-51.

14. Tian DH, Wan B, Bannon PG, Misfeld M, Lemaire SA, Kazui T, et al. A meta-analysis of deep hypothermic circulatory arrest versus moderate hypothermic circulatory arrest with selective antegrade cerebral perfusion. Ann Cardiothorac Surg. 2013;2:148-58. 